Article

\title{
Dealing with Superficial Femoral Artery Disease: An Ongoing Debate-Open vs. Endovascular Treatment-Preliminary Results
}

\author{
Andreea Luciana Rață ${ }^{1}$, Sorin Barac ${ }^{1, *}$, Roxana Ramona Onofrei ${ }^{2, *}$, Adela Dumitrașcu ${ }^{1}$ \\ and Mihai Ionac ${ }^{1}$ \\ I Department of Vascular Surgery, "Victor Babeș” University of Medicine and Pharmacy, 30004I Timişoara, \\ Romania; rataandreealuciana@gmail.com (A.L.R.); adelassı@yahoo.com (A.D.); mihai.ionac@gmail.com (M.I.) \\ ${ }^{2}$ Department of Rehabilitation, Physical Medicine and Rheumatology, "Victor Babeș” University of Medicine and \\ Pharmacy, 30004I Timișoara, Romania \\ *Correspondence: sorinbarac@gmail.com (S.B.); onofrei.roxana@umft.ro (R.R.O.); Tel.: +40-748331276 (S.B.); \\ +40-749108129 (R.R.O.)
}

Submitted: 27 September 2020; Accepted: 25 October 2020; Published: 30 October 2020

\begin{abstract}
I) Background: Both open surgery and endovascular strategies are accepted methods for the treatment of critical limb ischemia (CLI) due to superficial femoral artery disease (SFA). There is currently only one randomized trial results (BASIL-I) that compared open vs. endo procedures for SFA treatment. In this study, we wanted to compare two treatment strategies for superficial femoral artery vascular disease. (2) Material and methods: A study was conducted on 235 patients (part of a national project- "Development of the public infrastructure research and development and creation of new infrastructure") in which the open vs. endovascular strategy was compared in patients with critical limb ischemia and SFA disease. (3) Results: Primary outcomes are the time elapsed until major events related to the index leg or death. Secondary outcomes are amputation-free survival rate, reintervention on the index leg, major cardiovascular events and postoperative complications. (4) Conclusion: After 6 months, we had an overall mortality rate of $7.23 \%$ and an amputation-free survival of $89.36 \%$.
\end{abstract}

Keywords: superficial femoral artery; endovascular surgery; open surgery; revascularisation

How to cite: Cotoi, L.; Amzăr, D.; Sporea, I.; Borlea, A.; Schiller, O.; Schiller, A.; Pop, G.N.; Stoian, D. Dealing with Superficial Femoral Artery Disease: An Ongoing Debate-Open vs. Endovascular Treatment-Preliminary Results. Timisoara Med. 2020, 2020(I), Io; doi:Io.35995/tmj20200Ioro.

Introduction

Peripheral arterial disease (PAD) is currently considered a global pandemic that affected, in 20IO, approximately 200 million patients [I]. According to the latest guidelines of the European Society for Cardiology (ESC), from 2017, the annual incidence of major amputations (equally distributed between belowand above-the-knee) ranges between 120 and 500 per million in the general population [2]. Superficial femoral artery disease was, for decades, treated by open surgery. However, open surgery can have important 
limitations (like wound complications, long hospitalization, absence of a good vein conduit and the overall operative risk associated).

The 2017 ESC Guidelines recommendations on revascularization of superficial femoral (SFA) occlusive lesions are that an endovascular strategy should be attempted first for short lesions of under $25 \mathrm{~cm}$ (class I level C) $[3,4]$. However, there are only a few randomized trials that compare surgical versus endovascular therapy; a clear comparison of the two techniques is limited and a real randomization is difficult. The research aims to evaluate the comparison of endovascular vs. open surgery treatment strategies in patients with critical limb ischemia for the final purpose of limb salvages that are fit for both revascularization procedures (bypass surgery or endovascular strategy). The results presented in this study show that, for now, surgical bypass is a more effective and durable option for patients with low post-operative morbidity and mortality, but has longer hospitalization and higher wound complication rate.

Since 20I6, in the UK, Bypass vs. Angioplasty in Severe Ischemia of the leg_-2 (BASIL-2) has been conducted to compare the clinical and cost-effectiveness of a "vein bypass first" with a "best endovascular treatment first" revascularization strategy for severe limb ischemia due to below-the-knee disease The study is ongoing and the first results will be announced probably in 202I [5].

BASIL-3 is a pragmatic RCT for the UK, designed to compare the clinical and cost-effectiveness of plain balloon angioplasty with or without bail-out bare metal stenting, drug-coated balloon angioplasty with or without bail-out bare metal stenting, and primary stenting with drug-eluting stents for severe limb ischemia secondary to femoro-popliteal disease [6].

In this study, we wanted to compare two treatment strategies for the superficial femoral artery vascular disease open procedures versus new endovascular ones in terms of amputation-free survival rate and time elapsed until major events related to index leg occurred.

\section{Materials and Methods}

All patients included in this study were recruited nationwide. The major inclusion criteria was critical limb ischemia, as defined by chronic rest pain with an ankle brachial index $(\mathrm{ABI})$ under 0.40 , with an ankle pressure under $50 \mathrm{mmHg}$ or at hallux level under $30 \mathrm{mmHg}$, or with an $\mathrm{TcPO}_{2}$ under $30 \mathrm{mmHg}$ OR diabetic ulcer OR chronic lesion with no tendency to heal present for more than two weeks OR gangrene that involves any portion of the foot. Other inclusion criteria were: age above I $8 \mathrm{y}$, obtained informal consent, the possibility to perform either endovascular procedure or an open one, the presence of a good aorto-iliac inflow, the presence of a good outflow (in case a bypass procedure is performed) and the availability of additional laboratory testing in order to assess other risk factors for PAD.

The exclusion criteria were: any existence of a popliteal artery aneurysm on the index leg, life expectancy under two years because of other comorbidities, high risk of surgical intervention, acute vasculitis, Buerger disease, acute limb ischemia, any revascularization on the index leg prior to three months before inclusion, any suprainguinal revascularization prior to six weeks before inclusion, chemo/radiotherapy, pregnancy/lactation, participation in any clinical studies in the last 30 days before inclusion, patient's refusal to sign the informed consent, the requirement of an emergency revascularization procedure, contraindication for the use of iodine contrast solution.

The study has the approval of the Ethic Committee of the "Pius Brinzeu" County Clinical Emergency Hospital (No. 145/2017) under the EU GCP Directives, International Conference of Harmonization of 
Technical Requirements for Registration of Pharmaceuticals for Human Use (ICH), and Declaration of Helsinki and all included patients signed the informed consent.

After the assessment of the patients' laboratory, clinical and CT-angio testing, a group of surgeons analysed the patient to see if he meets the criteria for the study (i.e., the patient can be operated through either technique without affecting the revascularization outcome). Then, the patient was randomly (unequal randomization) allocated to one of the groups.

After the allocation of the patients to either the open or endovascular group, the intervention was performed rapidly. In this study, 235 patients were enrolled between December 2017 and December 2019. The baseline characteristics of the patients are detailed in Table I.

Table 1. Demographics of patients enrolled for revascularization.

\begin{tabular}{llll}
\hline Variable & Open Strategy (N/\%) & Endo Strategy (N/\%) & $p$ Value \\
\hline Patients & I34 (57.02) & IOI $(42.97)$ & 0.7687 \\
Age (years) & $64.94 \pm$ II & $67.44 \pm$ I2.I & 0.8753 \\
Male patients & IIO $(82.08)$ & $76(75.24)$ & 0.1265 \\
Indication & & & \\
Ankle pressure <50 mmHg & $49(36.56)$ & $23(22.77)$ & 0.0346 \\
Diabetic ulcer/chronic lesion & $43(32.08)$ & $31(30.69)$ & 0.0027 \\
Gangrene without healing tendency & $42(31.34)$ & $47(46.53)$ & 0.3456 \\
Hypertension & IO7 $(79.85)$ & $98(97.02)$ & $<0.00 \mathrm{I}$ \\
Chronic kidney disease & $28(20.89)$ & $56(55.44)$ & $<0.00 \mathrm{I}$ \\
Smoking (current or former) & $98(73.13)$ & $76(75.24)$ & 0.2388 \\
Dyslipidemia & $76(56.7 \mathrm{I})$ & $64(63.36)$ & $<0.00 \mathrm{I}$ \\
Diabetes mellitus & $87(64.92)$ & $74(73.26)$ & 0.2459 \\
Coronary artery disease & $45(33.58)$ & $39(38.6 \mathrm{I})$ & 0.0103 \\
\hline
\end{tabular}

Open procedures consisted of femoro-popliteal bypass (from the common femoral artery to proximal popliteal artery or from the superficial femoral artery to distal popliteal artery) with or without femoral endarterectomy using suitable vein or a prosthetic conduit. Endovascular procedures consisted of SFA angioplasty (either with plain balloon or with paclitaxel-coated balloons with/without stent placement).

Primary outcomes are the time elapsed until major events related to the index leg or death. Secondary outcomes are amputation-free survival rate, reintervention on the index leg, major cardiovascular events, and postoperative complications.

Follow-up is set to 30 days, 3-6-9-I2 months and then every year, for 5 years after the project ends. The data are registered on a platform developed inside the study.

When appropriate, values are presented as average \pm SEM (standard error). Values were compared with MedCalc Statistical Software version 19 (MedCalc Software bvba, Ostend, Belgium). Differences were considered statistically significant at $p<0.05$. 


\section{Results}

A total of 235 patients were enrolled, $134(57.02 \%)$ with open surgery and IOI $(42.97 \%)$ with an endovascular strategy. The majority were males (186-79.14\%).

The mean age was similar for the two groups; the patients in the endo group were more likely to have lesions and the open group had the most smokers.

The revascularization procedures are detailed in Tables 2 and 3.

Table 2. Open revascularization procedures characteristics.

\begin{tabular}{lll}
\hline Variable & Number & Percentage \\
\hline Surgical conduit & & \\
Common femoral to proximal popliteal artery bypass & 98 & 73.13 \\
Superficial femoral to distal popliteal artery bypass & 36 & 26.86 \\
Endarterectomy to common and deep femoral artery & $\mathrm{I} 8$ & $\mathrm{1} 3.43$ \\
\hline Graft conduit & & \\
Ipsilateral inverted great saphenous vein & 83 & $8 \mathrm{I} .37$ \\
Contralateral inverted great saphenous vein & 19 & 18.62 \\
Polyester grafts & 25 & 18.65 \\
Polytetrafluoroethylene grafts & 7 & 5.22 \\
\hline
\end{tabular}

Table 3. Endovascular revascularization procedures characteristics.

\begin{tabular}{lll}
\hline Variable & Number & Percentage \\
\hline Plain balloon procedure (single) & 53 & 52.47 \\
Plain balloon procedure (multiple) & 8 & 7.92 \\
Drug-coated balloon & $2 \mathrm{I}$ & 20.79 \\
Stent placement & $\mathrm{I} 9$ & $\mathrm{I} 8.8 \mathrm{I}$ \\
Residual stenosis $<30 \%$ & $\mathrm{I} 3$ & $\mathrm{I} 2.87$ \\
\hline
\end{tabular}

Endarterectomy procedure was performed in I8 cases, seven of them $(38.88 \%)$ requiring the insertion of an angioplasty synthetic patch because of the local situation (saphenous vein length and calibre).

Reintervention was required in I9 patients (14.17\%) from the open group and in four patients (3.96\%) from the endovascular group (Table 4 ).

The mean hospitalization period was six days in the open group and three days in the endovascular one.

Within the perioperative period until discharge, five major amputations (below the knee, two in the open group and three in the endo one) were performed because of extensive infection of the forefoot. A total of I7 minor amputations (i.e., toes or metatarsal) were also performed, with no significant statistical differences between the two groups. 
Table 4. Postoperative complications.

\begin{tabular}{llll}
\hline Variable & Open Group (N/\%) & Endovascular Group (N/\%) & $\boldsymbol{p}$ Value \\
\hline Emergency reintervention & $2(\mathrm{I} .49)$ & $2(\mathrm{I} .96)$ & 0.24 \\
Bleeding & $2(\mathrm{I} .49)$ & $2(\mathrm{I} .96)$ & 0.08 \\
Wound infection & $\mathrm{II}(8.20)$ & $\mathrm{O}(\mathrm{o})$ & $<\mathrm{O} .00 \mathrm{I}$ \\
Lymph leakage & $4(2.98)$ & $\mathrm{O}(\mathrm{o})$ & 0.03 \\
Myocardial infarction & $\mathrm{O}(\mathrm{O})$ & $\mathrm{I}(\mathrm{o}) .99)$ & 0.34 \\
Stroke & $2(\mathrm{I} .49)$ & $3(2.97)$ & 0.38 \\
Pneumonia & $\mathrm{I}(\mathrm{I} .49)$ & $\mathrm{I}(\mathrm{0.99})$ & 0.25 \\
Total & $22(\mathrm{I} 6.4 \mathrm{I})$ & $9(8.9 \mathrm{I})$ & $<0.00 \mathrm{I}$ \\
\hline
\end{tabular}

The randomization ended in December 2019. All patients had a 30-day follow-up. After that, there were nine patients lost to follow-up, six from the endovascular group and three from the open one. Figure i presents the CONSORT diagram for patients at 6 months follow-up.

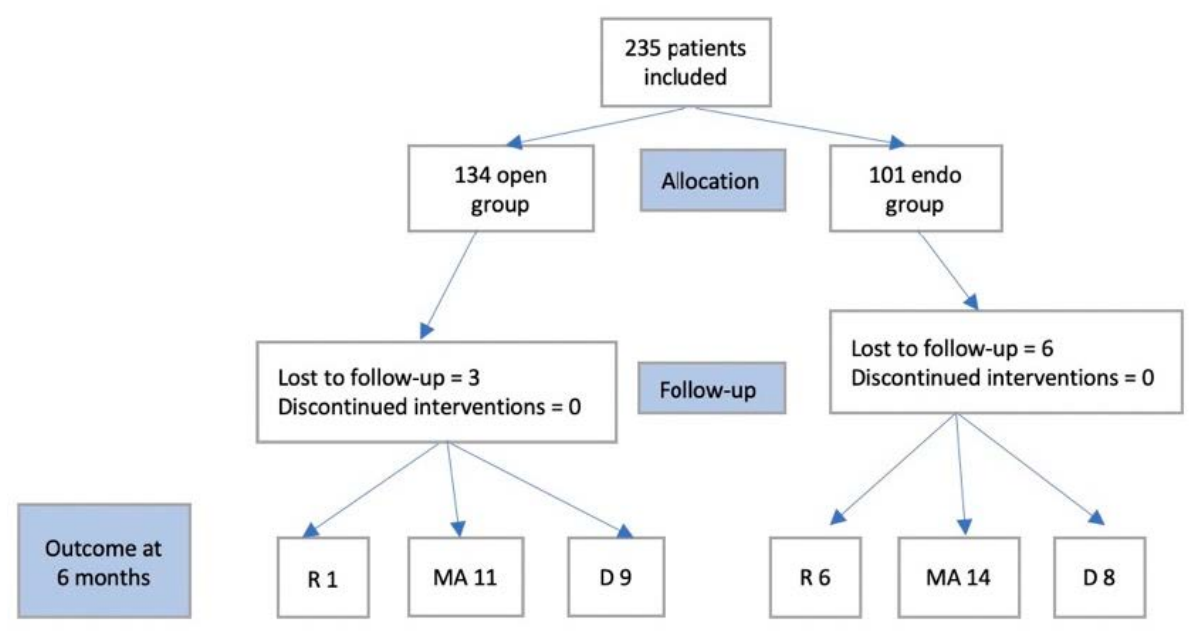

Figure 1. CONSORT diagram for patients after a six-month follow-up ( $\mathrm{R}$-reinterventions, MA-major amputations, D-deaths).

Mortality at 30 days was 2.55 (six patients, two from the open group and six from the endo one).

After six months, the overall mortality rate was 7.23\%. Patient status after a six-month follow-up is described in Table 5 .

Table 5. Patient status after a six-month follow-up.

\begin{tabular}{llll}
\hline Variable & $\begin{array}{l}\text { All Patients } \\
\text { (no/\%) }\end{array}$ & $\begin{array}{l}\text { Open Group } \\
\text { (no/\%) }\end{array}$ & $\begin{array}{l}\text { Endovascular Group } \\
\text { (no/\%) }\end{array}$ \\
\hline Lost to follow-up & $9(3.82)$ & $3(2.23)$ & $6(5.94)$ \\
Dead & I7 (7.23) & $9(6.7 \mathrm{I})$ & $8(7.92)$ \\
Alive with major amputation on the index leg & $20(8.5 \mathrm{I})$ & $9(6.7 \mathrm{I})$ & II (Io.89) \\
Reintervention for revascularization on the index leg & $7(2.97)$ & I (o.7) & $6(5.94)$ \\
\hline
\end{tabular}




\section{Discussion}

These results represent the only follow-up to date in Romania for this type of patients. If patient selection is appropriate, the type of intervention will not predict failure; either one of the procedures should lead to the same result.

A comparison between the two techniques is often limited and enrolment in comparative trials proved to be difficult.

The results are similar, though, to other studies from the literature, aiming towards an endovascular first approach in selected patients. All similar studies concluded that under 2 years, the preferred choice is endovascular, and for patients who have a life expectancy more than 2 years, the open strategy is more suitable, if a vein conduit is used.

The first randomized trial for open vs. endovascular for the treatment of severe ischemia of the leg was BASIL trial enrolled 452 patients with critical limb ischemia, with a follow-up of up to 5 years. An analysis after two years showed that the patients randomized to surgery had better clinical outcomes than those from the angioplasty group [7].

The enthusiasm for an endovascular first strategy is growing [8] and the vein bypass surgery is increasingly treated as an option after the endovascular procedures fail to have a good outcome or when endovascular strategies have been exhausted [9,I0].

The researchers from the BASIL trials are currently conducting BASIL-2 and BASIL-3 trials (the first one aims at randomizing 600 patients to endovascular-first vs. vein bypass-first and the second one, plain balloon angioplasty and/or bail-out bare metal stent, drug-coated balloon and/or bare metal stent, and drug-eluting stent).

McQuade trial compared synthetic bypass with nitinol-covered stent grafts in 86 patients, and concluded that, after a 4-year follow-up, the stent grafts had similar primary patency [II].

BEST Endovascular vs Best Surgical Therapy in Patients with Critical Limb Ischemia (BEST-CLI) is currently enrolling patients and will compare the efficiency of the best available treatment (open vs. endovascular) in critical limb ischemia [I2].

There are also a few non-randomized trials that compare open strategies with endovascular strategies. Dosluoglu et al. compared C and D SFA lesions above-the-knee ePTFE bypass vs. stenting for TransAtlantic Inter-Society Consensus II (TASC). They enrolled 127 patients with a technical success rate of $84 \%$ for TASC $\mathrm{C}$ and ${ }_{\mathrm{IO}} \%$ for TASC D lesions. They concluded that balloon angioplasty should be considered in TASC D lesions only in high-risk patients that cannot tolerate a bypass procedure [I3].

Syracuse et al. made a comparison of IIz bypass grafts and Ios endovascular procedures in SFA lesions without prior intervention. After three years, they did not find a difference in the freedom of reintervention. They concluded that surgical bypass (for the treatment of claudication) showed improved freedom of restenosis, but it was associated with an increased length in hospital stay and wound infection, similar to our findings [14]. 
A secondary analysis of the BASIL data was made in 2018 when Meecham et al. made a comparison of clinical outcomes between primary bypass and secondary bypass after failed plain balloon angioplasty in the BASIL trial and their work suggested that patients requiring secondary bypass after failed initial angioplasty do significantly worse than those who undergo primary bypass surgery [ 15$]$.

\section{Conclusions}

Our results show that, for now, surgical bypass is a more effective and durable option for patients with low post-operative morbidity and mortality. However, open surgery has a longer hospitalization (i.e., higher costs) and a higher rate of wound complications, as opposed to endovascular strategy.

If the endovascular strategy was the treatment of choice, one should preserve the inflow and outflow area of a potential bypass. Further research needs to be done in order to see the long-term results of these data.

Author Contributions: Conceptualization, A.L.R. and S.B.; methodology, A.L.R.; software, R.R.O.; validation, A.L.R., S.B., M.I. and R.R.O.; formal analysis, A.L.R. and R.R.O.; investigation, A.L.R. and A.D.; resources, A.L.R. data curation, A.L.R. and A.D.; writing-original draft preparation, A.L.R. and S.B. writing-review and editing, A.L.R., S.B., R.R.O., A.D. and M.I.; visualization, A.L.R., S.B., R.R.O., A.D. and M.I.; supervision, A.L.R.; project administration, A.L.R.; funding acquisition, A.L.R. and M.I.

Funding: This research was funded by Medical Academy of Sciences "Development of the public infrastructure research and development and creation of new infrastructure"-MySMIS project code I07I24.

Acknowledgments: The study is part of a national project on two different European Strategies, under the patronage of the Medical Academy of Sciences: Sectorial Operational Program (phase I-in which different hospitals all across Romania were equipped with 17 angiographs) and Competitiveness Operational Program (phase 2-research studies in the 17 national centres mentioned above). The study is conducted under the project- "Development of the public infrastructure research and development and creation of new infrastructure" - MySMIS project code IO7I24. The research is conducted in seven large cities in Romania-Timisoara (which is also the leader of the research), Bucharest, Brasov, Iasi, Suceava, Satu Mare, and Targu Mures.

Conflicts of Interest: The authors declare no conflict of interest.

\section{References}

I. Fowkes, F.G.R.; Rudan, D.; Rudan, I.; Aboyans, V.; O Denenberg, J.; McDermott, M.M.; E Norman, P.; A Sampson, U.K.; Williams, L.J.; A Mensah, G.; et al. Comparison of global estimates of prevalence and risk factors for peripheral artery disease in 2000 and 20I0: a systematic review and analysis. Lancet 2013, 382, 1329-I340. [CrossRef]

2. Aboyans, V.; Ricco, J.-B.; Bartelink, M.-L.E.L.; Björck, M.; Brodmann, M.; Cohnert, T.; Collet, J.-P.; Czerny, M.; de Carlo, M.; Debus, S. 2017 ESC guidelines on the diagnosis and treatment of peripheral arterial diseases, in collaboration with the European Society for Vascular Surgery (ESVS). Eur. J. Vasc. Endovasc. Surg. 2018, 55, 305-368. [CrossRef] [PubMed]

3. Lammer, J.; Zeller, T.; Hausegger, K.A.; Schaefer, P.J.; Gschwendtner, M.; Mueller-Huelsbeck, S.; Rand, T.; Funovics, M.; Wolf, F.; Rastan, A.; et al. Sustained Benefit at 2 Years for Covered Stents Versus Bare-Metal Stents in Long SFA Lesions: The VIASTAR Trial. Cardiovasc. Interv. Radiol. 2014, 38, 25-32. [CrossRef] [PubMed]

4. Lammer, J.; Zeller, T.; Hausegger, K.A.; Schaefer, P.J.; Gschwendtner, M.; Mueller-Huelsbeck, S.; Rand, T.; Funovics, M.; Wolf, F.; Rastan, A.; et al. Heparin-bonded covered stents versus bare-metal stents for complex femoropopliteal artery lesions: the randomized VIASTAR trial (Viabahn endoprosthesis with PROPATEN bioactive surface [VIA] versus bare nitinol stent in the treatment of long lesions in superficial femoral artery occlusive disease).J. Am. Coll. Cardiol. 2013, 62, 1320-1327. [PubMed]

5. Popplewell, M.A.; Davies, H.; Jarrett, H.; Bate, G.; Grant, M.; Patel, S.; Mehta, S.; Andronis, L.; Roberts, T.; Deeks, J.; et al. Bypass versus angio plasty in severe ischaemia of the leg-2 (BASIL-2) trial: Study protocol for a randomised controlled trial. Trials 2016, 17, II. [CrossRef] [PubMed]

6. Hunt, B.D.; Popplewell, M.A.; Davies, H.; Lewis, M.; Jarett, H.; Bate, G.; Grant, M.; Patel, S.; Hewitt, C.; Andronis, L.; et al. Ballon versus Stenting in severe ischemia of the leg-3 (BASIL-3)> study protocol for a randomized controlled trial. Trials 2017, 18, 224. [CrossRef] [PubMed] 
7. Bradbury, A.; Adam, D.J.; Bell, J.; Forbes, J.F.; Fowkes, F.G.R.; Gillespie, I.; Ruckley, C.V.; Raab, G.M. Bypass versus Angioplasty in Severe Ischaemia of the Leg (BASIL) trial: Analysis of amputation free and overall survival by treatment received. J. Vasc. Surg. 2010, 51, 18S-3IS. [CrossRef] [PubMed]

8. Bisdas, T.; Borowski, M.; Stavroulakis, K.; Torsello, G.; Adili, F.; Balzer, K.; Billing, A.; Böckler, D.; Brixner, D.; Debus, S.E.; et al. Endovascular Therapy Versus Bypass Surgery as First-Line Treatment Strategies for Critical Limb Ischemia. JACC: Cardiovasc. Interv. 2016, 9, 2557-2565. [CrossRef] [PubMed]

9. Joels, C.S.; York, J.W.; Kalbaugh, C.A.; Cull, D.L.; Langan, E.M.; Taylor, S.M. Surgical implications of early failed endovascular intervention of the superficial femoral artery. J. Vasc. Surg. 2008, 47, 562-565. [CrossRef] [PubMed]

ıo. Goodney, P.P.; Beck, A.W.; Nagle, J.; Welch, H.G.; Zwolak, R.M. National trends in lower extremity bypass surgery, endovascular interventions, and major amputations. J. Vasc. Surg. 2009, 50, 54-6o. [CrossRef] [PubMed]

II. McQuade, K.; Gable, D.; Hohman, S.; Pearl, G.; Theune, B. Randomized comparison of ePTFE/nitinol self-expanding stent graft vs prosthetic femoral-popliteal bypass in the treatment of superficial femoral artery occlusive disease. J. Vasc. Surg. 2009, 49, 109-116.e9. [CrossRef] [PubMed]

12. Best Endovascular vs. Best Surgical Therapy in Patients with Critical Limb Ischemia (BEST-CLI). Available online: https://clinicaltrials.gov/ct2/show/NCTo2060630 (accessed on is September 2020).

13. Dosluoglu, H.H.; Cherr, G.S.; Lall, P.; Harris, L.M.; Dryjski, M.L. Stenting vs above knee polytetrafluoroethylene bypass for TransAtlantic Inter-Society Consensus-II C and D superficial femoral artery disease. J. Vasc. Surg. 2008, 48, in66-i174. [CrossRef] [PubMed]

I4. Siracuse, J.J.; Giles, K.A.; Pomposelli, F.B.; Hamdan, A.D.; Wyers, M.C.; Chaikof, E.L.; Nedeau, A.E.; Schermerhorn, M.L. Results for primary bypass versus primary angioplasty/stent for intermittent claudication due to superficial femoral artery occlusive disease. J. Vasc. Surg. 2012, 55, I00I-I007. [CrossRef] [PubMed]

I5. Meecham, L.; Patel, S.; Bate, G.R.; Bradbury, A.W. Editor's Choice-A comparison of Clinical Outcomes between primary bypass and secondary bypass after failed plain balloon angioplasty in the Bypass versus Angioplasty for Severe Ischemia of the Limb (BASIL) Trial. Eur. J. Vasc. Endovasc. Surg. 2018, 55, 666-67I. [CrossRef] [PubMed]

(C) 2020 Copyright by the authors. Licensed as an open access article using a CC BY 4.0 license.

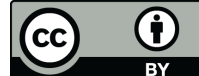

